\title{
NECESIDAD DE LA TRADUCCION EN LAS EMPRESAS Procesos y perfiles
}

Por:

Bibiana Clavijo, María Claudia Panqueva María Clara Correal, María Isabel Duque Edgar Mendoza, Carlos Franco y Jairo Alberto Galindo*

\section{ESUMEN}

Este artículo presenta los avances de investigación del grupo de investigación «necesidades de traducción en las empresas colombianas» encontrados en 34 empresas medianas $y$ multinacionales. Este avance formula la importancia de promover la formación especializada de traductores con un perfil específico para las organizaciones. Los resultados encontrados demuestran que el traductor que requiere la empresa actual es un intraempresario que genere valor agregado al manejar en forma ágil datos en lengua de partida y convertirlos en información en lengua de llegada dentro del contexto organizacional.

\section{Palabras clave}

Gestión del conocimiento, traducción en la empresa colombiana, lengua de partida, lengua de llegada, competencia traductora, perfil de traductor profesional.

\section{INTRODUCCIÓN}

E lenguaje es el eje fundamental a partir del cual todas las decisiones empresariales tienen su sustento. Por ello encontramos que el trabajador del conocimiento tiene como una de sus tareas más importantes, el entendimiento y capacidad de proposición frente a aspectos de misión crítica en su respectiva área de influencia organizacional.

Sin embargo, y muy contrario de lo que se pueda pensar, la gestión del conocimiento deja de ser cada día más un elemento teórico o de pura abstracción. Su desarrollo se encuentra cada vez más ligado a lo que los estudios de caso y las prácticas reales pueden permitir. El caso de $\mathrm{El}$ Banco de Desarrollo Islámico (BDI) es un claro ejemplo de ello. Cuando revisamos su gestión encontramos que «Reemplazar personal es fácil. Reemplazar el conocimiento del personal que deja la compañía es un reto mayor, un reto que el Banco de Desarrollo Islámico decidió afrontar poniendo a contar historias como el centro de su estrategia de gestión del conocimiento.» (Inside Knowledge,

\footnotetext{
* Profesores Facultad de Lingüística y Comunicación Organizacional Universidad EAN.
} 
2006). En su caso encontramos un eje de gran importancia: el uso del lenguaje para solucionar un asunto de gestión del conocimiento.

Este documento se encargará de revisar, mediante un enfoque empresarial y comunicativo, la incidencia e influencia de la traducción en los procesos de comunicación que se generan en ambientes organizacionales, en el desarrollo de las actividades, de las prácticas de las empresas. El alcance de este análisis se verá reflejado en la proyección en la universidad EAN, por primera vez en Colombia y de manera única en Iberoamérica, de una maestría en traducción orientada al campo empresarial, que se espera comience su primera promoción en el segundo semestre de 2007.

Comenzaremos por exponer una breve referencia al estado actual de las investigaciones y desarrollos en torno a la traducción, enfatizando en lo más esencial y puntual relacionado con nuestro objeto de estudio: la traducción en la empresa colombiana.

\section{Abstract}

This article presents the preliminary findings obtained in the study conducted by the research group "Translation Needs of Colombian Companies» in 34 medium size and multinational companies. It focuses on the importance of promoting specialized translator's graduate education according to the profile required by companies. The findings indicate that the translators, which current companies need, are intrapreneurs who add value to the company's information system. So they transform data from the source language into information in the target language.

\section{KeY WORDS}

Knowledge management, translation in Colombian Companies, source language, target language, translation competency, professional translator's profile. 


\section{LA IMPORTANCIA DE LA TRADUCCIÓN EN EL MUNDO ACTUAL Y POR ENDE EN LAS EMPRESAS}

T

ener al lenguaje y más específicamente a la palabra en dicho punto, en el centro de las prácticas empresariales, nos llevó a considerar un elemento que va ahora más allá y que alberga la proyección de la empresa en este esquema ya tan mencionado de la globalización: la internacionalización y estandarización de la economía. Aún cuando el idioma español se encuentre en alza y que las economías hispano- e iberoamericanas se proyecten a partir de una mayor concientización del valor del idioma, el inglés sigue y seguirá siendo por mucho tiempo el idioma del pensamiento económico y empresarial.

Como profesionales investigadores de diversas áreas relacionadas con los procesos de comunicación, especialmente en la lingüística y la traducción, encontramos que la conver-gencia lenguaje, comunicación y globalización, da la pauta para considerar que la traducción juega cada vez un mayor papel en el flujo de la información, y en general, en los procesos que se embarcan en la que ya conocemos como gestión del conocimiento.

La gestión del conocimiento se encuentra en este espacio en tanto las organizaciones, como entes orgánicos con dinámicas y flujos de información, implementan de forma consciente y proyectada o inconsciente y empírica, algún tipo de mecanismo para orientar la consecución y la producción de algún bien, servicio o recurso. $\mathrm{Y}$, aunque no se haga de forma explícita, dicho producto siempre tendrá su componente comunicativo (factura, contrato, documento legal, compromiso, certificado, constancia, carta, comunicación forma o informal...). Es así como la gestión del conocimiento, en la esfera de la traducción, contempla la gestión de los productos de conocimiento, vistos como productos comunicativos derivados de las transacciones que se desarrollan en la empresa.

\section{ESTADO DEL ARTE EN EL CAMPO DE LA TRADUCCIÓN}

$\mathbf{P}$

ara poder llegar a proponer un modelo de traducción o de traductor para las empresas y alcanzar a demostrar la necesidad de investigación y estudio de la traducción enfocada en las organizaciones, es primordial tener en cuenta primero un breve panorama de lo que comprende ser traductor o ejercer dicha función en un contexto general.

\section{1 ¿Qué es ser un traductor?}

Cualquier persona que ejerza la profesión de traductor afirma con ello poseer un buen conocimiento de la lengua a partir de la que traduce (lengua de partida) y de la lengua en la que se expresa (lengua de llegada). Esta última debe ser, de preferencia, la lengua materna o una lengua de la que posea el mismo grado de conocimiento que el de su lengua materna, de igual modo que los escritores poseen dicho conocimiento de la lengua en la que escriben. Esta persona debe poseer una competencia traductora (Hurtado, 2001), que, a su vez, se desglosa en subcompetencias lingüísticas, extralingüísticas, instrumentales y profesionales, psicofisiológicas, competencia de transferencia textual y competencia estratégica, tanto verbal como no verbal. Visto de otro modo, ser traductor comprende, en parte, tener un conocimiento complejo de por lo menos dos lenguas, dos culturas, dos modos de representar el mundo. 


\section{En Colombia}

El ejercicio de traductor es un oficio reconocido por el estado colombiano, específicamente por una Corporación de la Rama Judicial': «El Artículo 1 del Decreto 0382 de febrero 19 de 1951 del Consejo Superior de la Judicatura se refiere a los traductores como auxiliares de la justicia...» «El Artículo 4 del Decreto 0382 de 1951 se refiere al examen para el ejercicio del oficio de traductor e intérprete oficial ...». (Letts, 2006). Cuando alguna persona (y subrayamos en ello, cualquier persona), se siente con las competencias para servir de traductor profesional, asiste a una universidad autorizada mediante el Artículo 4 de la ley 92 del 8 de Julio de 2005 del Congreso de la República, y presenta una serie de pruebas formales que lo acreditan como traductor oficial. El único prerrequisito para presentar dichas pruebas consiste en poseer un dominio adecuado de las lenguas en las que se desea obtener la acreditación otorgada mediante resolución del Ministerio de Justicia, documento que se debe inscribir ante el Ministerio de Relaciones Exteriores. (Letts, 2006)

Por último, en el Código de Ética del Traductor (ACTI, 2000) se entiende por traductor a la persona natural cuya actividad social es, entre otras, la traducción, sin importar la disciplina con la que se relacione la obra traducida, ya sea como traductor independiente o a sueldo, en jornada completa o en jornada parcial y que cumple además los siguientes requisitos:

- Comprueba estudios superiores y una vasta cultura general.

- Demuestra un buen conocimiento de la lengua a partir de la cual traduce, pero sobre todo el dominio de aquella a la cual traduce.
El ejercicio del traductor es un oficio reconocido por el Estado colombiano, específicamente por una Corporación de la Rama Judicial.

Según exploración realizada en el Colegio Colombiano de Traductores, y con mayor precisión en el Encuentro Nacional de Traductores Babel VI, realizado del 13 al 16 de octubre de 2006 en la ciudad de Bogotá D.C., podemos hablar de un perfil de traductor en Colombia.. Actualmente, quien se desempeña como traductor es una persona que trabaja desde su oficina para varios clientes ya sean individuos o personas que solicitan servicios de traducción de texto o de interpretación. Se le llama traductor freelance y su trabajo depende de su competencia para darse a conocer en el mercado.

Otro aspecto a considerar en el perfil del traductor es la escasa formación especializada que ofrecen las universidades colombianas. A pesar de la demanda que existe al respecto, según el interés demostrado por los participantes del Encuentro Nacional de Traductores (150 personas provenientes de 15 universidades nacionales e internacionales) no existen suficientes programas especializados en traducción. No hay maestrías en traducción en Colombia; como posgrado sólo se ofrecen especializaciones. En Bogotá, el único programa que existe es la Especialización en Traducción Inglés - Español de la Universidad del Rosario que inició en 1994 y en otras ciudades la Universidad de Antioquia, Universidad del Valle, Universidad de Pamplona y la Universidad Autónoma de Manizales que ofrecen variedad temática en sus programas.

\footnotetext{
1 En la República de Colombia, «la Constitución de 1991 reorganiza y consolida la organización del poder público en las tres ramas tradicionales del sistema democrático, a saber, la ejecutiva, la legislativa y la judicial. La rama judicial está integrada por la Fiscalía General de la Nación y el Consejo Superior de la Judicatura. El sistema de tribunales consta de dos jurisdicciones principales, la ordinaria y la militar.» Tomado de Naciones Unidas «Informe del Relator Especial sobre la Independencia de Jueces y Abogados sobre la visita a Colombia» En: http://www.hchr.org.co/documentoseinformes/documentos/html/informes/ onu/reija/E-CN-4-1998-39-ADD-2.html Revisado el 9 de noviembre de 2006.
} 
Aunque la traducción no se considera como una profesión, ni existe reglamentación clara al respecto, el único parámetro de calidad actualizado que existe es el examen de traducción oficial (Letts, 2006): «El Artículo 4 de la Ley 962 del 08/07 de 2005 reglamenta el examen para el ejercicio del oficio de traductor e intérprete oficial: Toda persona que aspire a desempeñar el oficio de traductor e intérprete oficial deberá aprobar los exámenes que sobre la materia dispongan las universidades públicas y privadas que cuenten con facultad de idiomas debidamente acreditadas y reconocida por el ICFES o la entidad que tenga a cargo tal reconocimiento».

Como futuro estándar de calidad, la red de terminología COLTERM encabezada por la Universidad de Antioquia está encargada de elaborar las normas ISO/TC 37/SC sobre traducción y terminología. Este proyecto constituirá una base clara sobre la cual se regule la traducción en Colombia.

Pese a la escasa regulación y a la escasa formación especializada de quienes ejercen como traductores, la realidad del país en este ámbito requiere una gran demanda. Las empresas multinacionales, mediana empresa y en general empresas exportadoras solicitan servicios de traducción con gran frecuencia. La mayoría tienen criterios estandarizados para la selección de traductores, así como volumen creciente de documentos a traducir como base para decisiones empresariales.
Aunque la traducción no se considera como una profesión, ni existe reglamentación clara al respecto, el único parámetro de calidad actualizado que existe es el examen de traducción oficial

\section{En hispanoamérica}

En sentido general, se destacan Chile, México y Argentina como los países con los sistemas (educativos y legales) más dispuestos y desarrollados para el ejercicio del oficio de traductor. Por ejemplo en Argentina, se encuentra Escuela y Sindicato de Traductores, todos orientados como auxiliares de los departamentos (ministerios) de justicia y de derecho.

\section{En el mundo}

En este recorrido general, podemos subrayar de modo especial la necesaria labor del traductor en una comunidad (Comunidad Económica Europea CEE) con más de 25 países, 13 idiomas y un sinnúmero de dialectos. En Europa la función de traductor es siempre, aunque una labor intermedia, fundamental en el desarrollo de cualquier acción civil, legal o social que permita la comprensión de las naciones ${ }^{2}$.

Como vemos, el traductor cumple en algunas sociedades una función que supera el ámbito de la intermediación y llega a servir de facilitador en la ejecución de tareas bastante disímiles a la tarea inicial de estudioso de la lengua.

\footnotetext{
2 Para mayor información acerca de asociaciones y entidades que agremian o vinculan traductores, consulte http:// www.lexicool.com/translator_associations.asp?IL=3. o http://www.lai.com/samerica.txt. Revisado el 9 de noviembre de 2006.
} 


\subsection{Desarrollo de la traducción como ciencia ${ }^{3}$}

Después de haber abordado aspectos genéricos de ubicación geográfica y legal del oficio de traductor, podemos pasar al sentido que quizás tiene más desarrollo en el campo de la traducción: su investigación y desarrollo. La función y el establecimiento del oficio de traductor no tienen historia aislada de la propia escritura y la interacción comercial entre los pueblos. La diversidad de lenguas descrita bíblicamente dio paso a la necesidad de superar fronteras lingüísticas en pos de beneficios y transacciones comerciales a todo nivel.
Filósofos como Platón, religiosos como San Jerónimo (Patrono de los traductores en el mundo) y escritores como Cortázar, Poe y Baudelaire han sido protagonistas en el desarrollo de la ciencia de la traducción.

Revisar más allá el desarrollo e investigación de la traducción en el sentido literario sería ahondar en personalidades como Rosenblat,García Yebra e incluso a Martínez de Sousa, por citar algunos autores hispanoamericanos. Por ello, a continuación nos observaremos aspectos más enfocados al fenómeno traducción en su desarrollo y aproximación a la empresa colombiana.

\section{ESQUEMA TRADICIONAL DE LA TRADUCCIÓN}

$\mathbf{E}_{1}$ objeto final de una traducción es el claro entendimiento de las intenciones y sentido comunicativo de un autor en la preparación de un texto. Un traductor debe ser conocedor no solo de la temática que se desarrolla en el texto, sino de múltiples aspectos que rodean el núcleo de la interacción comunicativa.

\subsection{Procesos y metodologías de la traducción}

Establecer o definir los procesos más idóneos a seguir para obtener una buena traducción tiene como respaldo la investigación de diversos autores y teorías que han mostrado que se trata de un proceso en el que hay dos fases determinantes: «la fase de comprensión del texto de partida y la fase de la expresión de su mensaje, de su contenido, en la lengua receptora o de llegada»(García Yebra, 1982). Esto equivale a decir que, en la fase de comprensión, se decodifica el sentido del texto de partida en una actividad de construcción de significado. En esta fase, la interpretación juega el papel más importante, porque es en la que el traductor inicia un proceso de recodificación hacia la lengua de llegada. Para realizar dicha decodificación, planeada en virtud de la lengua de llegada, se tienen en cuenta distintos niveles de análisis en los segmentos originales del texto: desde las unidades mínimas de sentido que pueden ser palabras, frases o varias oraciones del texto de la traducción, hasta el texto completo considerado como una unidad de traducción.

\footnotetext{
3 Las primeras traducciones fueron de la Biblia, ya que como los judíos llevaban mucho tiempo sin hablar su lengua (el hebreo), ésta se perdió y las Santas Escrituras debieron traducirse para que las entendiesen los judíos que no hablaban la lengua original. Ptolomeo Filadelfo en el siglo III adC mandó traducir del hebreo al griego las Sagradas Escrituras a 72 sabios que dominaban tanto el hebreo como el griego. Esta versión se conoce como versión Alejandrina. En el siglo II D.C. se hizo una traducción de la Biblia al latín (Antiguo y Nuevo Testamento). Esta versión recibió el nombre de «Vetus Latina». Tomado de http://www.traduccion.at/2.html Traducción S.A. Revisado el 9 de noviembre de 2006.
} 
Podría considerarse que bajo aquel proceso de traducción, teniendo un pleno conocimiento de las lenguas inmersas en la traducción, todo se puede reducir a una sencilla comparación o como la etimología del concepto traducir lo define, al simple cambio de palabras y frases de una lengua a otra. Sin embargo, como no es así de sencillo, el proyecto de traducción automática ha tenido durante su evolución tantos tropiezos. Traducir en cualquier contexto y por cualquier canal ${ }^{4}$ demanda un gran esfuerzo, una serie de operaciones cognitivas más complejas, que tienen por finalidad construir el sentido completo del texto origen y su estructura, reconociendo en ella con profundidad y con conciencia metódica, aspectos como la gramática, la semántica, la sintaxis y quizás lo más importante, la cultura de las dos lenguas. Se recomienda por ello que el profesional traduzca a su lengua materna y conozca el tema o área de la traducción.

Algo que siempre es claro para todo aquel que se sumerge en el terreno de la traducción, es que no siempre es posible traducir los textos con estructuras totalmente equivalentes, razón por la cual, el traductor recurre con frecuencia a diversos procedimientos para asegurar la traducción de un texto determinado.

Algunos de los procedimientos a los que recurre un traductor son los siguientes (López Guix et al., 1997)5: La adaptación o traducción libre. El préstamo (p.ej. blue jeans, pizza, delikatessen). El calco léxico (p.ej. fútbol a partir de footbalI). La modulación. La equivalencia. La traducción literal. Este tipo de traducción es legítima sobre todo entre lenguas que comparten una misma cultura (Vinay y Dalbernet, 1958).

Hasta este punto, todo el proceso de traducción se ha visto desarrollado desde una perspectiva un poco ajena al desarrollo de la tecnología informática. Aunque regularmente la traducción es realizada por humanos, frecuentemente se recurre al uso de recursos informáticos, como las memorias de traducción.

Este componente, cada vez más inmerso en cualquier proceso y más de índole cognitivo, ha alcanzado un desarrollo tal, que la traducción logra un mayor grado de penetración en todos los niveles de desarrollo humano, conforme el sujeto o la sociedad avanza en el dominio de la herramienta. No sería errado decir que el grado de globalización e internacionalización que han tenido las distintas sociedades permite que la comunicación mejore entre distintas culturas, de la misma manera que se ve mediado y potenciado por el desarrollo y aprovechamiento de la tecnología. Dicho mejoramiento se posibilita gracias a los avances que la traducción ha podido implementar en materia de programación, software y hardware específicos.

\subsection{La especialización del oficio de traductor}

El traductor profesional, conforme va desarrollando su labor en una sociedad, tarde o

\footnotetext{
${ }_{4}$ El proceso mediante el cual se realiza traducción por medios escritos en tiempo diferido, recibe el nombre de Traducción, en contraste con aquel que se realiza por medios acústicos o audio-orales que se distingue con el nombre Interpretación. La referencia a traducción simultánea es considerada como una acepción errada, aunque sea aceptada por la Academia de la Lengua (Traducción Simultánea: La que se hace oralmente al mismo tiempo que se está pronunciando un discurso, conferencia, etc.).

5 Por no ser el objetivo del presente documento la profundización en los métodos de traducción, algunos aspectos teóricos se reducen a citas o referencias para mayor contextualización.
} 
temprano se ve obligado a delimitar su campo de acción a ciertas áreas específicas; se ve obligado a especializarse en su oficio. Del mismo modo, quien no es traductor por oficio, sino porque su contexto y sus competencias lo requieren y lo permiten, aunque domine perfectamente las estructuras de las lenguas necesarias, rara vez podrá traducir cualquier tipo de texto, 0 los textos de cualquier área del conocimiento: la especialización es casi obligatoria.

El uso de lenguajes profesionales para la traducción de textos exige entonces al traductor ponerse en el lugar de quien emite el mensaje, es decir, del especialista, y asumir sus mismas competencias. De esta forma, para cumplir su función de intermediario de la comunicación, deberá simular un conocimiento de la materia y de su especificidad cognitiva, así como de los elementos léxicos de la especialidad (Cabré et al., 2000). Sin embargo, el modo en el que el traductor adquiere este como mediador interlingüístico de la comunicación especializada, necesita poseer como mínimo cuatro competencias o habilidades: a. competencia lingüística en las dos lenguas con las que trabaja (de los recursos léxicos, sintácticos y estilísticos), b. competencia cognitiva en el dominio en cuestión (es decir, una competencia de comprensión de la materia técnica que traduce, que incluye el dominio del campo terminológico de la especialidad.), y c. un buen dominio de las convenciones de los géneros textuales en cada una de las lenguas participantes en la traducción.

Ya en recientes investigaciones se ha llegado a un acuerdo para conferir a este conjunto de habilidades y destrezas el concepto que citamos anteriormente: «competencia traductora» (Hurtado, 2001). Dichos elementos, con los que finalmente el traductor ha de contar para desempeñarse como tal en una organización, y que de cierta manera se encuentran en un vocabulario mucho más general, son (Páez et al, 2006): Conocimientos lingüísticos, capacidad de lectura en la lengua de partida y capacidad de redacción en la lengua de llegada. Conocimiento de los elementos extralingüísticos (contexto, intención, frases hechas...) de la lengua de partida. Competencia lectora, es decir, comprensión y producción de textos y Predisposición al cambio lingüístico ${ }^{6}$.

Además de contar con una serie de habilidades y destrezas propias, que son identificadas o descritas por una u otra teoría, el traductor cuenta con una gran cantidad de recursos, que se han perfeccionado conforme al área en la cual su trabajo también se perfecciona y se internacionaliza o desarrolla en diversas culturas. Algunos de estos recursos son los repertorios léxicos (diccionarios, enciclopedias, vocabularios, léxicos, bases de datos, bancos de datos, etc.) elaborados con una metodología sistemática y una serie de informaciones útiles para la toma de decisiones en el proceso de la traducción. Un diccionario no sólo le debe ofrecer al traductor aquella información que se considera necesaria sobre los conceptos, sino que también debe incluir información enciclopédica, relativa al conocimiento extralingüístico. Para el traductor efectivo en las organizaciones, encontramos que dicha herramienta se sustituye o complementa en ocasiones por recursos informáticos o por su propia experiencia y dominio del arte.

\footnotetext{
${ }^{6}$ «Cambio lingüístico», es el nombre que reciben en general las modificaciones o transformaciones que, en su evolución histórica, experimentan las lenguas y específicamente algunas palabras, tanto en los ámbitos del significado, como de la propia escritura. Por ejemplo, no obstante refieren el mismo objeto, se utilizan las palabras paradero y estación, o tocineta y bacon; de otro lado, en inglés la palabra «windows» que pasa de ser un objeto físico a un sistema operativo.
} 


\subsection{La traducción y el aporte de la tecnología informática}

Consideramos necesario puntualizar en este acápite en tecnología informática, dado que desde sus inicios, el oficio de traductor se ha valido de distintas tecnologías, llámense diccionarios, glosarios o campos semánticos.

La tecnología a la que nos referimos de aquí en adelante, la que tiene que ver con procesamiento sistemático y digital de la información, no dejó de lado los desarrollos que ya la traducción análoga había alcanzado. Hoy en día los métodos de traducción análoga se valen de las implementaciones de la traducción digital y viceversa. (Usamos traducción digital en lugar de electrónica solo por generalización, ya que tampoco queremos motivar un disenso en cuanto a los usos de digital, virtual, electrónico o computacional).

Considerando así a la traducción como una industria (editorial, científica, social, etc.), encontramos que la superación de la llamada brecha digital, conlleva la superación de los límites que la traducción también pueda poseer.

Mucho de lo que se puede comentar ahora en traducción y sus avances, toca de lleno el campo de los distintos tipos de interacción humano-computador, llámese traducción
El uso de lenguajes profesionales para la traducción de textos exige entonces al traductor ponerse en el lugar de quien emite el mensaje, es decir, del especialista, $y$ asumir sus mismas competencias.

automática, máquina de traducción, traducción asistida por computador o incluso traductor web, todos parten del mismo fundamento y llegan a la misma dificultad: la existencia de una "gramática universal» y la imposibilidad de traducir proverbios, citas, expresiones y en general componentes con algún tipo de carga semántica ${ }^{7}$. Reconociendo entonces la importancia e influencia de este ámbito de la traducción, tenemos que observar también que dado el peso de los condicionamientos existentes para que las empresas implementen conscientemente herramientas tecnológicas (factor económico, alfabetización digital y destinación de recursos), no podemos considerar por ahora el factor tecnológico como una variable regular para el análisis de los procesos de traducción en las empresas. Aunque se tiene en cuenta, para los fines de este documento no profundizamos en los pro o en los contra o en las alteraciones que la tecnología produce en la elaboración de traducciones en las organizaciones; este campo será objeto de un estudio posterior.

\footnotetext{
7 A pesar de los múltiples intentos, la gran demanda de capital que tuvo en sus inicios y la dispersión de grandes y pequeñas empresas y aplicaciones de traducción (systran, altavista, yahoo y hasta google), o traductores especializados por temáticas (Globalink o PowerTranslator Pro) la traducción «ideal» sigue siendo realizada únicamente por seres humanos.
} 
Después de precisar las condiciones que obligan a un traductor (profesional o empírico), tenemos que subrayar que su formación es muy importante puesto que hay una gran solicitud de él en el mercado, por esta razón se busca encontrar un perfil que demuestre su competitividad para afrontar con criterio propio y eficacia la traducción de un texto especializado.

Tratamos de puntualizar una definición de la traducción y el perfil del traductor profesional, con el fin de hacer una comparación entre el servicio que prestan los traductores automáticos y el traductor mismo, y así lograr crear una sola concepción de cuál sería la función de un traductor de textos técnicos o especializados en una organización.

Ahora bien, el traductor profesional es una persona que tiene un amplio conocimiento del léxico, la gramática y el uso de la lengua origen y posee un excelente dominio de su lengua materna que seguramente siempre será a la que traduce. Esta persona está constantemente actualizada con respecto a los acontecimientos culturales, políticos y sociales que suceden en los países de ambas lenguas y de esta forma interpreta y expresa el pensamiento de una lengua a otra.

El traductor, mediador entre dos interlocutores hablantes de distintas lenguas, ejerce su función poniéndose en el lugar de quien emite un mensaje y asume sus mismas competencias.
Si no lo hace, difícilmente hará una buena traducción. Asumir las competencias de un productor de texto especializado comporta conocer la materia específica, controlar su contenido y manejar la terminología que lo expresa. Para conseguir que el texto de traducción sea, en relación al original, literal en cuanto a contenido, gramatical en su expresión, adecuado en sus modalidades y ajustado estilísticamente, debe acercarse lo máximo posible a los usos léxicos que habría seleccionado el productor del texto, si se hubiera expresado naturalmente en la lengua de partida.

En la mayoría de los casos, los traductores experimentados son profesionales de diversas áreas, no simplemente lingüística, que tienen proficiencia en dos lenguas y culturas, y quienes en su mayoría han vivido en otros contextos culturales. Estos traductores se especializan en la traducción de documentos de un área específica. Es decir, son personas con conocimientos en un área del saber específica, que iniciaron hace muchos años a traducir y aún se mantienen en este oficio.

Tanto los unos (traductores profesionales), como los otros (traductores empíricos) se desenvuelven en los procesos comunicativos de las empresas. Es importante, sin desvincular o llegar a juzgar la labor de cada uno, considerar la especialización de aquellas personas que se dedican a este trabajo, bien sea en la formación de competencias traductoras o en la especialización de las mismas.

\section{En la mayoría de los casos, los traductores experimentados son profesionales de diversas áreas, no simplemente lingüística, que tienen proficiencia en dos lenguas y culturas, $y$ quienes en su mayoría han vivido en otros contextos culturales.}




\section{EXPLORACIÓN DE LAS NECESIDADES DE TRADUCCIÓN EN EMPRESAS COLOMBIANAS}

A lo largo del presente documento hemos expuesto nociones básicas de traducción, tanto desde el marco legal, como el comercial y aplicado de forma general a las organizaciones. En todo el recorrido se ha podido observar el poco desarrollo en investigación, aplicación y legislación que tiene este campo. Todo ello sirve de motivación y fundamento para demostrar una vez más, la razón para estudiar las necesidades de traducción en un campo tan específico como lo es la empresa, la organización colombiana.

A continuación, procedemos con la presentación cada vez más puntual de los avances de la investigación propuesta por el grupo de investigación lingüística, comunicación y traducción empresarial de la facultad de lingüística y comunicación organizacional de la universidad EAN, que precisamente ha servido de marco para este documento y que explora las necesidades de traducción en las empresas contemporáneas.

En consecuencia, este estudio busca dar respuesta a las siguientes preguntas de investigación: ¿Cómo se gestiona la traducción en las empresas medianas y grandes del país? Y ¿cuáles son sus necesidades de formación de expertos en traducción para contextos relacionados con economía, finanzas y negocios internacionales?

Como punto de partida para el propósito de este estudio exploratorio, presentamos sus objetivos:

«...Objetivo general: diseñar un perfil de traductor que desarrolle las competencias traductoras que requiere el sector empresarial colombiano, desde la exploración de la traducción como proceso de gestión lingüística y comunicativa en las organizaciones.

\section{Objetivos específicos}

- Explorar las necesidades de traducción de empresas en Colombia

- Establecer oportunidades actuales o potenciales de desempeño en traducción

- Generar líneas de investigación en traducción especializada....»

Ni el conocimiento del concepto de traducción, como tampoco el reconocer sus campos de acción, puede brindar una visión más cercana a las necesidades de formación y especialización de aquellos que se dedican -como dijimos, de modo profesional o por contexto y competencias previas (conocer el idioma) - al arte de la traducción, como lo puede brindar la realización de un estudio puntual de aquellos aspectos que desde la comunicación y la traducción inciden en la gestión del conocimiento que se desarrolla en la empresa.

La metodología utilizada para dicha investigación es la siguiente: a comienzos del segundo semestre académico de 2006, un total de 60 encuestas fueron aplicadas en diferentes empresas, las cuales proporcionaron una muestra de 34 medianas empresas y multinacionales, entre las que se encuentran Avianca, la embajada norteamericana, Bankvision Software Ltda., Chevron Texaco y el Citibank, en la ciudad de Bogotá, D.C. El criterio utilizado para la selección de dicha muestra fue el que se estuviesen llevando a cabo procesos reales de traducción en la empresa. La siguiente gráfica presenta los porcentajes de las empresas de la muestra por sectores de la industria. 


\section{Gráfico 1}

Representación esquemática del porcentaje, por sectores económicos, en los que se encuentran las empresas encuestadas

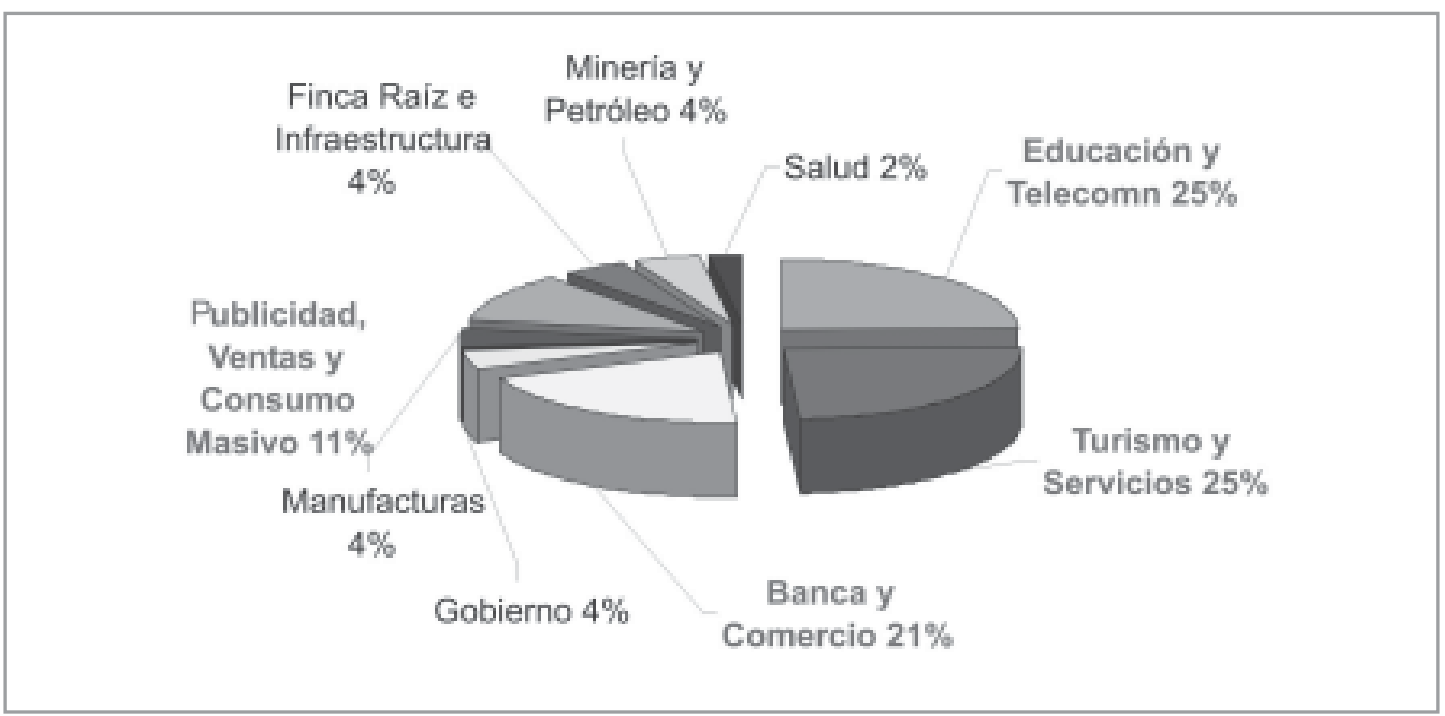

Las preguntas permiten, en una fase exploratoria previa al análisis que se merece, preparar una segunda fase de investigación que permita identificar más claramente algunos aspectos que si se dan solo por inferencia no son plenamente reconocibles.

Es así como por ejemplo, uno de los resultados nos presenta (véase gráfico 2) el valor que le dan las empresas a la realización de una traducción:

Gráfico 2

Representación esquemática de uno de los resultados de la encuesta. Pregunta 10 ¿Qué valores se tienen en cuenta para promover la realización de una traducción?

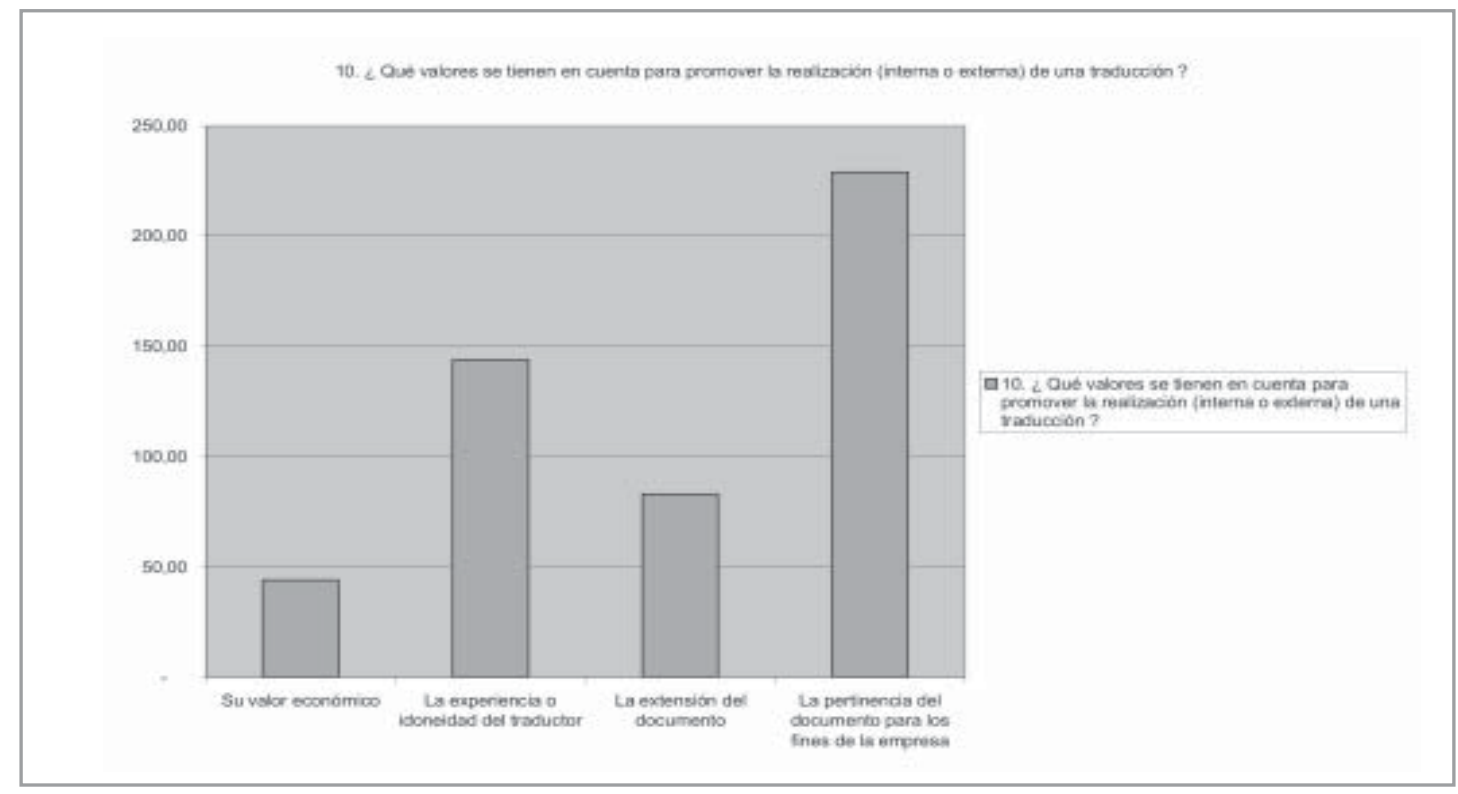


La diferencia entre los porcentajes nos puede hacer suponer que el valor económico de la traducción y la extensión del documento a traducir son variables que no influyen sustancialmente en la realización de una traducción, como sí sucede con la pertinencia del documento para los fines de la empresa y en menor porcentaje, la experiencia o idoneidad del traductor.

Otros resultados de esta fase de la investigación nos muestran que el $69 \%$ de las empresas utiliza su propio traductor, mientras que el $31 \%$ restante utiliza un traductor interno (in-house). Asimismo, la selección del traductor se hace bajo el criterio de que tenga principalmente conocimiento de la lengua ( $54 \%$ ), de que sea especializado en el área (24\%) o de que sea un traductor oficial (19\%). La traducción escrita es la más utilizada ( $77 \%$ ) en contraste con la oral y se realiza en gran medida de inglés a español (62\%), seguida por español-inglés $(32 \%)$. Otras lenguas involucradas en la traducción, en muy bajo porcentaje, son: francés-español $(2 \%)$ y, con un $1 \%$, españolfrancés, alemán-español y español-portugués.

En casi la mitad de las veces, el criterio utilizado para realizar traducciones es la pertinencia del documento para los fines de la empresa (45\%), seguido por la experiencia o idoneidad del traductor (29\%), la extensión del documento $(17 \%)$ y, por último, su valor económico (9\%). Además, tales traducciones son solicitadas principalmente por mandos medios de la empresa, subgerentes, subdirectores o coordinadores (47\%) y, en menor porcentaje, por los directivos (29\%), por empleados de menor jerarquía (19\%) o por personal externo o de otras empresas (4\%).

Una vez realizada la traducción, ésta es sometida a un proceso establecido institucionalmente (35\%), corregida por quien la solicitó $(27 \%)$ o permanece en trámite por algún tiempo (16\%).
Sin embargo, casi una quinta parte de las traducciones (22\%) son almacenadas y no se utilizan en absoluto. Además, la mayoría de las veces, las traducciones quedan en poder de quien las solicitó $(52 \%)$ y, con menor frecuencia, son base para negociaciones o trámites pertinentes a la visión de la empresa $(21 \%)$, son dirigidas a una base común o a un departamento (18\%) o son analizadas en grupo $(9 \%)$.

Finalmente, la necesidad y la fiabilidad del resultado de una traducción son determinadas, en la gran mayoría de las veces, por la persona que la necesita (85\%), por una unidad especializada ( $8 \%$ ) o por la unidad de recursos humanos $(7 \%)$.

Si combinamos algunos de los anteriores resultados podremos, a primera vista, llegar a suponer o inferir varias afirmaciones; sin embargo, solo realizaremos algunas aproximaciones que posteriormente podremos sustentar con mayor análisis.

Algunos de los resultados expuestos anteriormente, permiten concluir que, en general, el traductor freelance es requerido en casos puntuales, pues la mayor parte de la comunicación en otras lenguas es manejada y realizada internamente en la empresa; y quien actúa como traductor in-house es un miembro de la empresa que conoce las dos lenguas, aunque no siempre tiene especialización en el área correspondiente. La mayor demanda actual en traducción es escrita, en mayor volumen de inglés a español que de español a inglés y los directores de departamentos y coordinadores de área son quienes más solicitan estos servicios.

Esto nos indica que al momento de la contratación, el factor bilingüismo como valor agregado va ganando terreno frente al factor profesional en traducción, ya que de cierto 
modo un profesional puede llegar a hacer parte de una empresa simplemente por sus conocimientos de los idiomas que la empresa maneja, y que eso, el dominio del idioma puede ser más importante que el dominio de los temas que la empresa maneja. Y por otra parte, podemos suponer que la formación de traductores útiles para las empresas sigue siendo de corte más orientado a la escritura y la redacción de documentos (traducción propiamente dicha), que a la interpretación (oral) de textos en diversas lenguas, y que éstas son en el contexto de las empresas en Colombia, preminentemente el inglés y el español, existiendo una fuerte necesidad de profesionales con conocimientos de traducción que tengan al idioma inglés como fuente.

Por otra parte, se encontró además, que las traducciones no se integran al Sistema de Información de la Empresa (SIE), debido a que son realizadas para personas específicas. Por lo tanto, no se comparte el conocimiento que ellas generan. En suma, la traducción no está integrada al SIE, sino que depende de criterios individuales.

Finalmente, resulta válido decir que, en la actualidad, al igual que siglos atrás, la traducción ha sido y es una fuente que genera conocimiento, pero este conocimiento así generado no es aprovechado ni sistematizado por las empresas. El momento económico y cultural que viven las empresas requiere SIEs claros que integren y gestionen el conocimiento de las mismas $y$, como un agente importante en dicha gestión, el traductor es y será clave para la gestión del conocimiento empresarial.

En este marco, las organizaciones necesitan contratar múltiples servicios de outsourcing, entre ellos los servicios de traducción. De la misma forma, el servicio de traducción es generalmente monolingüe y las organizaciones de hoy solicitan servicios de traducción en diferentes lenguas que conforman la gama de los negocios.

Por otra parte y según la experiencia de los profesionales de lenguas modernas durante su práctica docente y los egresados que se encuentran desempeñando sus funciones, el traductor no tiene tareas permanentes de la empresa por lo que sus servicios son contratados muy esporádicamente. Esto trae como consecuencia factores que afectan esta actividad desde el punto de vista interno y externo, lo cual resulta en un alejamiento de este profesional, que aún formando parte como eslabón importante de la cadena dentro la empresa, queda fuera del verdadero contexto que vive la organización en el día a día. 


\section{Propuesta de Gestión}

Sin duda alguna, el sector empresarial colombiano requiere a su vez de una fuerte línea de investigación que siente nuevas pautas para la evaluación del acto de traducir como una necesidad real de la empresa contemporánea.

Si se tiene en cuenta que el traductor decodifica un mensaje en la lengua de partida para codificarlo de nuevo en la lengua de llegada, interpretando las mediaciones del mundo actual, la traducción se concibe como un acto complejo de comunicación que afecta a dos espacios comunicativos diferentes, en los que intervienen muchos elementos más allá de los lingüísticos o textuales. No es simplemente un proceso entre dos lenguas diferentes sino entre dos culturas diferentes, es un proceso de comunicación intercultural (Hurtado, 2001).

Ampliando este concepto al mundo contemporáneo, la labor de muchos traductores, que con escasa formación se desempeñan en forma independiente, se vería opacada por la nueva imagen del traductor empresarial. El contexto socioeconómico actual no requiere simplemente de traductores pasivos que certifiquen la fidelidad de los documentos traducidos como receptores de solicitudes de traducción fragmentadas del cúmulo de documentos que circulan en una empresa, sin que cumplan un papel de orientación, seguimiento ni planeación del proceso traductor empresarial como base de la competitividad en el desarrollo de la empresa.

Es evidente la necesidad de aumentar la competitividad y productividad de las empresas y organizaciones, hecho que solo se puede lograr con el desarrollo de profesionales altamente competitivos, formados en traducción especializada que generen valor a la empresa. Profesionales que conciban la traducción como proceso que facilita la gestión del conocimiento permiten asimilar, adaptar, generar y dar continuidad al conocimiento requerido por las empresas para enfrentar la competitividad y la globalización.

El traductor que requiere la empresa actual es un intraempresario que genere valor agregado al manejar en forma ágil datos en la lengua de partida y convertirlos en información en lengua de llegada dentro del contexto organizacional. Es quien integra información al Sistema de Información Empresarial (SIE), de forma tal que valida documentos que constituían simplemente datos en la lengua de partida. Es un traductor con productos que generan conocimiento, que al integrarse al Sistema de Información Empresarial, le permiten participar en la toma de decisiones y en la resolución de problemas de la empresa. En síntesis, es el traductor quien hace que sus productos apoyen la gestión del conocimiento empresarial.

El valor agregado de este traductor, como ente activo en la empresa, se basa en la elaboración, procesamiento y entrega de resultados, donde la información se considera el bien intangible que establece una conexión clara entre traducción y comunicación empresarial. Por esta razón, la gestión de la traducción empresarial es otro término clave que entraría a tener valor en las empresas como el marco dentro del cual se concibe la traducción organizacional. El nuevo esquema de la traducción se sintetiza en el siguiente diagrama: 
Gráfico 3

Representación esquemática de la evolución y aplicación de los procesos de traducción hacia la gestión empresarial

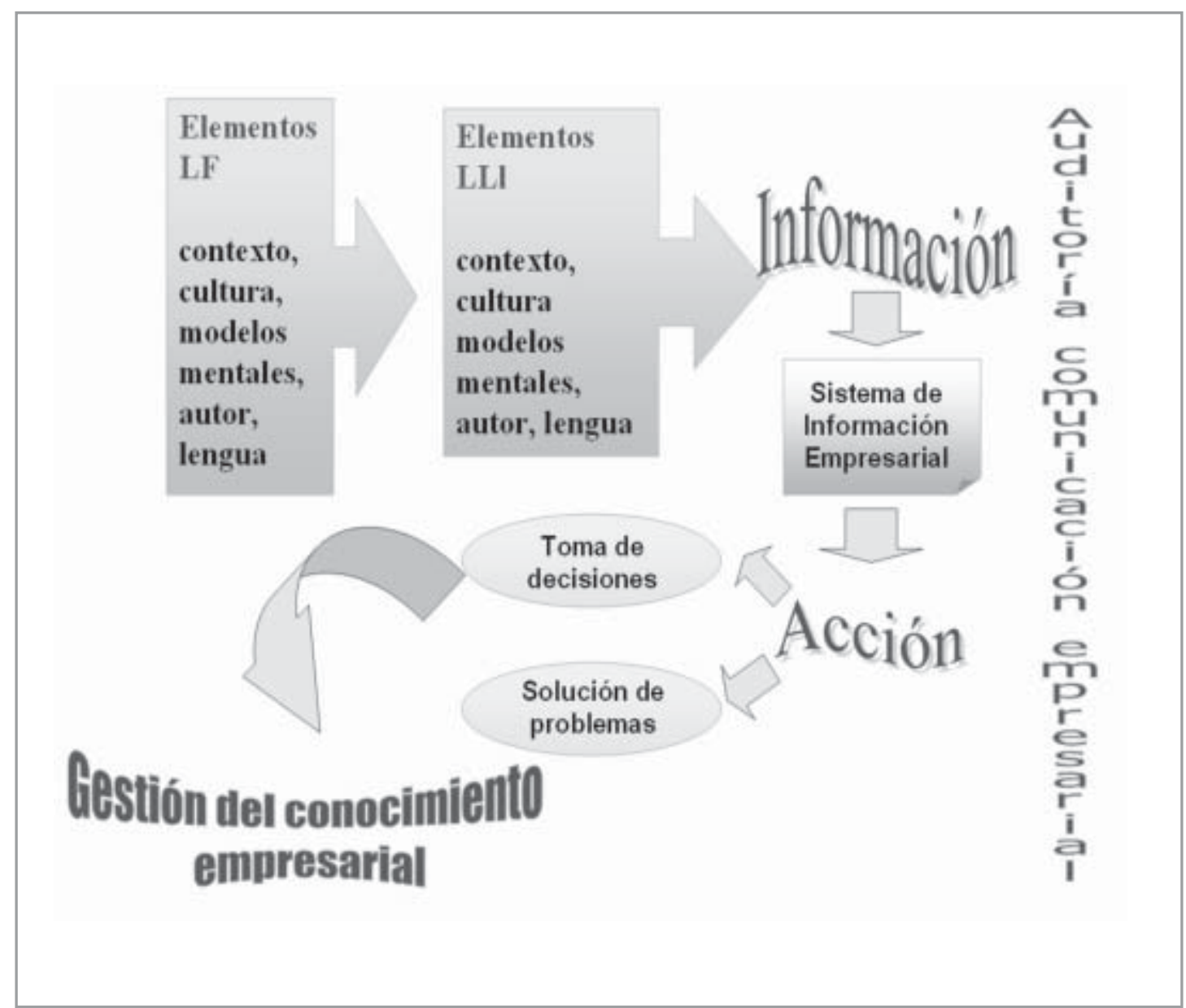

Fuente: Tomado de la ponencia presentada en el Encuentro Nacional de Traductores, Babel IV. 


\section{RECOMENDACIONES}

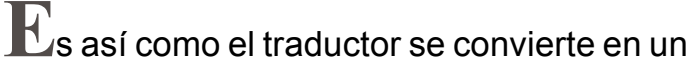
miembro activo de la empresa, en un mediador lingüístico y cultural inteligente, parte esencial del proceso de comunicación organizacional. Se constituye en profesional de la traducción con competencias de transferencia, lingüísticas, extralingüísticas, psicofisiológicas, instrumentales, profesionales y estratégicas (Hurtado, 2001: 397) para producir en otra lengua una versión de un documento original que convierte datos en la lengua fuente en información en la lengua de llegada, con el fin de generar conocimiento dentro de la organización. Este modelo de traductor maneja los bienes intangibles de la empresa. Es un «knowledge worker» de la empresa contemporánea, un asesor de inteligencia empresarial que traspasa barreras cognitivas, lingüísticas y culturales.

La esencia de esta propuesta está centrada en una revisión de los procesos de desempeño profesional del traductor especializado como agente del conocimiento empresarial y gestor del cambio, unido a una mirada del ejercicio traductor que lo equipare a un asesor de contenidos bilingües, editor de información en red y lector inteligente de los entornos competitivos de las corporaciones. Un perfil de traductor organizacional altamente competitivo que integre conocimiento enciclopédico de los distintos sectores empresariales, lenguas, culturas y recursos tecnológicos especializados que le permitan satisfacer las necesidades de las empresas contemporáneas que buscan procesos de integración y relaciones comerciales cada vez más globalizadas.

Esta investigación representa un primer paso en la consolidación de un modelo de traductor y de especialista en la traducción que la empresa actual en su interacción tanto comercial como comunicativa, debe poseer.

El traductor del mundo actual necesita ser parte del entorno empresarial para el cual realiza este tipo de ejercicio, necesitando desarrollar tanto competencias comunicativas, como linguísticas y culturales muy fuertes, convirtiéndose en un comunicador especializado con manejo de nuevas tecnologías relacionadas con su ejercicio y un alto sentido de compromiso y ética. Todo esto se relaciona con las áreas de gestión del conocimiento y la comunicación organizacional en los contextos de un mundo globalizado. 


\section{BiblogRAFíA}

ACTI. (Asociación Colombiana de Traductores e Intérpretes) 2000. Código de ética del traductor. En: http://www.tradulex.org/Regles/eticaACTI.htm Revisado el 9 de noviembre de 2006.

CABRÉ, T. 1993. La terminología: Teoría, metodología, aplicaciones. Barcelona: Antártida/ Empúries. ISBN: 84-7596-405-2; 978-84-7596-405-8.

. 2000: «Terminología y documentación». En C. Gonzalo García, y V. García Yebra. Eds. Documentación, Terminología y Traducción. Madrid: Ed. Síntesis y Fundación Duques de Soria.

GARCÍA YEBRA, Valentín. 1982. Teoría y práctica de la traducción [Obra completa]. Gredos. Madrid. ISBN: 84-249-1840-1; 978-84-249-1840-8-

GONZALO GARCÍA, Consuelo; GARCÍA YEBRA, Valentín. 2000. Documentación, terminología y traducción. Síntesis. Madrid. ISBN: 84-7738-748-6 ; 978-84-7738-748-0 -

HURTADO ALBIR, Amparo. 2001. Traducción y Traductología. Introducción a la traductología. Cátedra. Madrid. ISBN: 84-376-1941-6; 978-84-376-1941-5-

INSIDE KNOWLEDGE 2006. Case study: Islamic Development Bank En: http:// www.ikmagazine.com/display.asp?articleid=C0662F8D-ADE1-49A7-856E-C3711838881E Revisado el 9 de noviembre de 2006.

- Case study Islamic Development Bank. En: InsideKnowledge. Septiembre de 2006. Vol. 10. p. 24.

LETTS, ANTHONY. 2006. Recopilación de algunas disposiciones de Ley que puedan afectar a los traductores en Colombia. Mimeo.

LÓPEZ GUIX, Gabriel ; MINETT WILKINSON, Jacqueline. 1997. Manual de traducción ingléscastellano : teoría y práctica Gedisa. Madrid. ISBN. 84-7432-552-8; 978-84-7432-552-2.

MUÑOZ MARIN, Javier; VALDIVIESO BLANCO, María 2006. Traductores y especialistas en la Unión Europea, hacia un binomio integrador. En: (Caché de Google) http://64.233.161.104/ search?q=cache:AilOnK748dQJ:europa.eu.int/comm/translation/events/almagro/html/ munoz_valdivieso_corri_es.htm Revisado el 9 de noviembre de 2006. [La fecha corresponde al registro de almacenamiento de la página según el buscador].

OROZCO JUTORÁN, Mariana. 2000. Instrumentos de medida de la adquisición de la competencia traductora. Universidad Autónoma de Barcelona. Servicio de Publicaciones = Universitat Autònoma de Barcelona. Servei de Publicacions. ISBN: 84-490-2014-X; 978-84-490-2014-8

PÁEZ PEREZ, Vilma; SALVADOR ESCALANTE, Batista. Sin fecha. Traducción y Comunicación. En: Revista Comunicación. Versión digital de la Revista del Instituto Tecnológico de Costa Rica, publicada por la Escuela de Ciencias del Lenguaje. http://www.itcr.ac.cr/revistacomunicacion/ traduccion_y_comunicacion.htm. Revisado el 9 de noviembre de 2006.

VINAY, J-P. y DALBERNET, J. 1958. Stylistique comparée du français et de l'anglais. Méthode de traduction. Paris, Didier. ISBN: 2278008943. 